\title{
Self-Reported Nonadherence Associated with Pharmacy and Home Medication Management Inconvenience Factors in a US Adult Population
}

This article was published in the following Dove Press journal: Patient Preference and Adherence

\author{
Rebecca J Bartlett Ellis (D) \\ Deanna Hertz ${ }^{2}$ \\ Patrick Callahan ${ }^{3}$ \\ Todd M Ruppar (iD) ${ }^{4}$ \\ 'Department of Science of Nursing Care, \\ Indiana University School of Nursing, \\ Indianapolis, IN, USA; ${ }^{2}$ Ipsos Ltd., South \\ Lake Tahoe, CA, USA; ${ }^{3}$ Becton, \\ Dickinson and Company, San Diego, CA, \\ USA; ${ }^{4}$ Department of Adult Health and \\ Gerontological Nursing, College of \\ Nursing, Rush University, Chicago, \\ IL, USA
}

Purpose: Medication nonadherence is a significant and multidimensional problem contributing to an increased risk of morbidity and mortality. Inconveniences in pharmacy and home contexts may increase nonadherence. This research examined inconveniences in pharmacy and home contexts associated with self-reported nonadherence, controlling for demographic and medication-taking covariates.

Methods: Data from 4682 individuals who reported self-managing medications in an online marketing survey between October and December 2017 were analyzed in this secondary analysis. Nonadherence was dichotomized using a single question about likelihood to take medications as prescribed (adherence=always; nonadherence $=$ most of the time, some of the time, never). Multivariable logistic regression with backwards elimination was used to examine the pharmacy (use of home delivery, number prescriptions picked up and visits to pharmacy) and home context (method used to organize/manage medications, satisfaction, and bother with management) variables and the demographic (age, sex, race/ethnicity, education, income, insurance) and medication (number of oral medications, medication changes and frequency of taking) covariates associated with nonadherence.

Results: Overall, $25.8 \%$ of the responses indicated nonadherence. Nonadherence was more likely for individuals making fewer separate pharmacy trips (OR 0.98; 95\% CI 0.97-0.99); picking up fewer prescriptions (OR 0.96; 95\% CI 0.93-0.99); never, rarely or sometimes using mail order compared with always (OR 1.71; 95\% CI 1.30-2.26); not satisfied with managing medications (OR 2.13; 95\% CI 1.42-3.19); and using pill pouches and being bothered by them (OR 8.28; 95\% CI 1.83-37.31). Using pill pouches or a pillbox and not being bothered by them significantly decreased nonadherence likelihood. Younger and female respondents and those reporting medication changes in the last year were also more likely to report nonadherence.

Conclusion: Though reasons for nonadherence are multidimensional, this study suggests that inconveniences in both the pharmacy and home context are important. Improving adherence requires addressing issues of inconvenience across the care continuum.

Keywords: medication adherence, medication compliance, community pharmaceutic services, outpatient, drug packaging, behavior and behavior mechanisms, $\mathrm{MeSH}$

\section{Introduction}

Approximately $75 \%$ of all interactions with healthcare facilities involve drug therapy, ${ }^{1}$ yet an estimated one out of three Americans do not take their medications as prescribed, ${ }^{2}$ known as nonadherence. Nonadherence can result from not initiating treatment, poor implementation (eg, missing or skipping doses), and early discontinuation of therapy. ${ }^{3}$
Department of Science of Nursing Care, Indiana University School of Nursing, 600 Barnhill Drive, E423, Indianapolis, IN 46202, USA

Tel +I 3172740047

Email rjbartle@iu.edu 


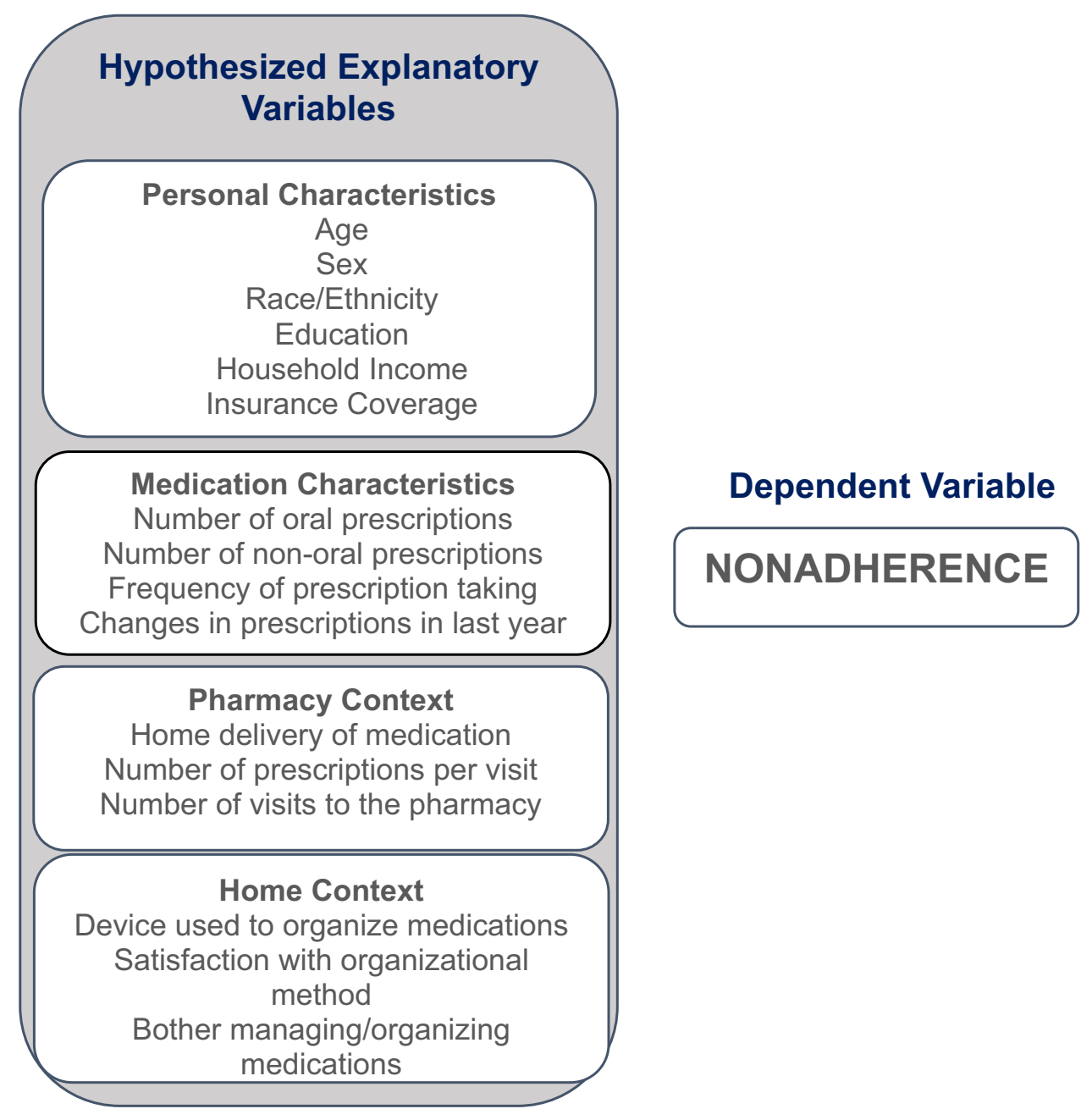

Figure I Context-specific variables likely associated with nonadherence.

Nonadherence increases the risk of hospitalization, morbidity, and premature mortality ${ }^{4}$ and contributes to an estimated $\$ 290$ billion annually in avoidable health system costs. ${ }^{2,5}$ Due to associated high costs and morbidity, researchers and healthcare providers should consider ways in which they can make managing and adhering to prescribed medications more convenient for patients.

Much of the adherence research to date has been disease-, population- or medication-specific, identifying a wide variety of factors impacting nonadherence: More than 200 factors have been attributed to nonadherence. ${ }^{2}$ Evidence from systematic and meta-analytic reviews reflect that across studies predictors do not reliably produce the same results and in some cases conflict with one another. ${ }^{6-8}$ The World Health Organization's framework for medication nonadherence reflects that nonadherence is multidimensional, ${ }^{2}$ yet studies often focus on only one dimension of nonadherence and little attention has focused on the interrelationships of contexts that represent the patients' continuum of accessing and managing medications. ${ }^{9}$ The pharmacy and home management contexts are key parts of the adherence continuum..$^{10}$ In the pharmacy context, convenience factors such as willingness to wait in line for prescriptions ${ }^{11}$ and use of mail order pharmacies to obtain prescriptions may impact patient adherence. In the context of home management, people are tasked with creating routines, preparing correct dosing, using prompts, and self-monitoring to maintain adherence. As such, people use a variety of methods to organize medications such as the original packaging from the pharmacy, pillbox organizers, and other types of convenience packaging devices. ${ }^{12}$ Packaging device effectiveness ${ }^{13}$ is likely related to how satisfied patients are with the device. These multidimensional aspects of managing and organizing medications in pharmacy and home contexts are likely to affect nonadherence. A better understanding of 
how these factors impact nonadherence is important for designing interventions to support adherence across the care continuum.

The purpose of this study was to examine relationships between aspects of pharmacy and home medication management and self-reported medication nonadherence, controlling for demographic and medication-taking variables. In this study, the aspects of interest represent conveniences and inconveniences in the medication management process in the pharmacy and home contexts. For the purpose of this study, inconvenience refers to situational aspects that: 1) increase steps or add complexity in acquiring medication, or 2) add processes or complications associated with managing and administering medication. Approaches to addressing inconvenience include, but are not limited to, reducing or eliminating trips to the pharmacy and simplifying methods of organizing and tracking medication. Understanding these pharmacy and home medication management aspects will provide important new context-specific information that reflects the continuum of individuals' medication management. We believe this will be important for future work to develop interventions that target both the pharmacy and home contexts.

\section{Methods}

This secondary analysis used existing survey data that was originally collected between October and December 2017. The dataset used for this secondary analysis was deidentified and therefore did not meet the definition of human subjects research $^{14}$ as determined by the Indiana University Institutional Review Board [Review Number 2001947912].

\section{Participants}

The original survey data were collected for market research purposes to understand adults' experiences using pharmacies and managing medications. Participants were recruited by email invitation sent to online panels and a multi-sourced opt-in panel recruited using e-mail recruitment, affiliate networks, and website advertising using the KnowledgePanel $^{\circledR}$ (Ipsos, Ltd). ${ }^{15-17}$ Eligible respondents were adults (18 years and older) who had visited a pharmacy at least twice in the past 6 months, with at least one visit having taken place within the past month. Respondents had at least some involvement in the selection of pharmacy location, either making the decision themselves or together with someone else. Additionally, respondents must have been prescribed at least one daily prescription. The original survey data were collected online after screening eligibility was determined based on survey responses and individuals indicated that they agreed to participate as a response option. The time to complete the full online survey was approximately 30 mins and respondents received $\$ 5$ in compensation at completion. This secondary analysis is restricted to participants who independently managed their own medications and responded to one survey question asking about medication taking that was used to establish adherence status in this study, as further described below.

\section{Procedures}

Selection of variables representing aspects of medication management and organization in pharmacy and home contexts was based on the available survey data, prior literature, and guided by the Medication Adherence Contexts and Outcomes (MACO) Framework. ${ }^{10,18}$ The MACO framework posits that outcomes of medication adherence and medication nonadherence result from processes that occur within distinct yet interrelated contexts. These contexts include clinic encounters, pharmacy encounters, and dayto-day home management and underlie the continuum of an individual's medication management. For the purposes of the present study, we focused on the contexts of pharmacy and day-to-day home management to select variables that we hypothesized would be associated with medication nonadherence (Figure 1).

\section{Variables from Survey Questionnaire Demographic and Medication Characteristics}

Available data included age, sex, race, ethnicity, education, household income, number of oral prescriptions, frequency of prescription medication taking, and changes in prescribed medications in the last year. Age was reported as years on a continuous scale. The other variables were categorical. Sex was reported as male or female. Race consisted of 6 response options in which respondents could select "yes" or "no" options for each category (White, Black or African American, American Indian or Alaskan Native, Asian, Native Hawaiian or other Pacific Islander, and Other). Education was reported as the highest degree obtained with four categories (less than high school, high school, some college, and bachelor's degree or higher). This variable was also dichotomized into categories of "high school or less" and "more than high school education". Household income was comprised of five categories $(\$ 19,999$ or less, $\$ 20,000-39,999$, $\$ 40,000-59,999$, $\$ 60,000-99,999, \$ 100,000$ or greater) and represented the 
total household income earned in the prior 12 months before taxes. Number of oral prescriptions and nonoral medications taken daily were classified into three categories (one, two, and three or more). Similarly, frequency of prescription medication taking was categorized into three categories representing how many times per day medications were taken (Once a day, 2 times a day, and 3 or more times a day). Changes in prescribed medications in the past year were treated as a dichotomous variable with "yes" or "no" options.

\section{Pharmacy Context}

Data for understanding the pharmacy context were derived from three survey questions about obtaining medications from pharmacies. The first question asked how often the individual used a mail order, online, or home-delivery pharmacy service to obtain medications with response options "Always", "Some of the time", "Rarely", "Never". This question was dichotomized for analysis to compare those "always" using mail order to a separate category combining all other responses. The second question asked participants to identify the average number of individual prescriptions picked up per brick and mortar pharmacy visit and was measured on a continuous scale. The third question asked individuals to identify the number of separate trips made to a pharmacy on a monthly basis and was treated as a continuous scale variable.

\section{Home Management Context}

Data about the home context were derived from three survey questions focused on aspects of medication management that represent experiences in the home context: 1) methods used to organize medications, 2) satisfaction with organization methods, and 3) how bothered individuals are with organizing medications. Methods used to organize medications included 4 categories (original packaging/bottles, pillboxes, pill pouches and some other type of organization method). Satisfaction was a dichotomous variable in response to a question asking about respondents' overall satisfaction with the current method for managing and organizing medications at home (satisfied, not satisfied). How bothersome respondents found organizing medications was measured on a 4-point Likert-type scale with options "Not at all bothersome", "not too bothersome", "somewhat bothersome", and "very bothered". The variable used for analysis combined the options representing any level of bother ("not too bothersome", "somewhat bothersome", and "very bothered") to create a dichotomous variable with categories "bothered by organizing medications" and "not bothered by organizing medications".

\section{Medication Adherence Status}

A single self-report question asked participants to rate in general how likely they were to take their daily oral prescribed medications and over the counter supplements prescribed by a doctor, rated on a 4-point scale ("always", "most of the time", "only some of the time", "almost never"). For the present analysis, the World Health Organization's adherence definition guided dichotomizing the response options to create the category of adherence ("always") and nonadherence ("most of the time", "only some of the time" and "almost never"). While this singleitem measure of medication adherence has not been validated, it is similar to other single-item scales that have been used to screen for medication adherence. ${ }^{19-21}$

\section{Data Analysis}

Analyses were performed using SPSS Statistics for Windows, Version 25.0 (IBM Corp. Armonk, NY). Descriptive statistics appropriate for the measurement level (eg, frequencies and percentages for nominal/ordinal; mean and standard deviation for continuous variables) were used. Independent t-tests were used to compare the means of continuous variables and the chi-square tests were used to test differences in proportions of categorical variables between the nonadherent and adherent groups. An iterative binary logistic regression analysis approach was used to examine relationships between pharmacy and home medication management context factors and self-reported medication nonadherence, controlling for demographic and medication-taking variables. First, univariate analysis of each independent variable was performed with the selection criteria set at $\mathrm{p} \leq 0.25$ as recommended by Hosmer, Lemeshow \& Sturdivant. ${ }^{22}$ The multivariable model containing all covariates identified by univariate analysis was fit with logistic regression analysis using the backward step likelihood ratio method. Subsequently, two-way interactions between each of the pharmacy and home management context variables (Hosmer, Lemeshow \& Sturdivant, 2003) were examined and the possible two-way interaction between age and organizational device was examined based on prior literature. ${ }^{12}$ Interactions were selected using criteria of $\mathrm{p} \leq 0.01$ for addition to the multivariable model. Multivariable analysis selection was based on removal criteria of 0.10. Crosstabs, standard errors and collinearity were examined prior to running the multivariable logistic regression analysis. Model fit to the 
observed data was determined using chi-square statistics $(\mathrm{p}<0.05)$.

\section{Results}

\section{Demographic and Medication-Taking Characteristics}

A total of 4,862 survey responses met inclusion criteria and were included in this analysis. Table 1 reflects the demographic and medication-taking characteristics of the sample. The sample predominantly identified as white $(40.9 \%)$, female $(59.6 \%)$, educated beyond the high school level $66.9 \%$ ), and the majority reported having some type of healthcare insurance to cover prescription medications (94.9\%). On average, the sample managed 4 prescriptions daily, with $47.4 \%$ reporting taking medications once daily. Prescription changes were reported by $58.9 \%$ of the sample, and individuals reported that most changes occurred once per year or less often than that.

\section{Medication Adherence and Medication Nonadherence Likelihood}

Nonadherence was self-reported by $25.8 \%(n=1209)$ of the respondents. Comparisons between those who reported medication nonadherence and adherence likelihood and the demographic and medication-taking characteristics are reported in Table 1. Those who reported nonadherence likelihood, were on average younger, female, and had more education and tended to report income earnings at the middle to upper end. Additionally, those reporting nonadherence also reported they took on average fewer oral medications $(p=0.08)$ and had experienced changes to prescription medication regimens $(p<0.001)$ in the past year. No differences were found with respect to race and ethnicity or total number of non-oral prescribed medications taken daily between the two groups. All other demographic and medication-taking characteristics significantly differed between the two groups. A summary of the pharmacy and home context variables and differences between adherent and nonadherent groups are shown in Table 2.

\section{Logistic Regression Analyses}

Binary logistic regression analyses were conducted to examine the relationships between nonadherence likelihood and the "Pharmacy context" variables (number of medications picked up from the pharmacy, separate trips made to pharmacy, use of mail/home delivery of medications) and "Home context" variables (use of an organizing device, management satisfaction, organization burden). All six independent variables representing pharmacy and home contexts were significantly associated with nonadherence likelihood in separate univariate analyses $(\mathrm{p} \leq 0.25)$. When examining all possible two-way interactions between each of the pharmacy and home context variables using separate logistic regression analyses, the only significant interaction found was between the method used to organize/manage medications and being bothered by managing medications $(p=0.005)$. The additional hypothesized interaction between method used to organize/manage medications and age, based on prior literature, was not significant $(p=0.752)$ and therefore was not included in the multivariable model.

Multivariable logistic regression with backwards elimination was used to examine the pharmacy (use of home delivery, number prescriptions picked up and visits to pharmacy) and home context (method used to organize/manage medications, satisfaction, and bother with management) variables and the demographic (age, sex, race/ethnicity, education, income, insurance) and medication (number of oral and non-oral medications, medication changes and frequency of taking) covariates associated with nonadherence likelihood. The two-way interaction between method used to organize/manage medications and being bothered by managing medications was also included in the analysis. Results of the multivariable logistic regression analysis are presented in Table 3. The final multivariable model was statistically significant, $\chi^{2}(15, \mathrm{~N}=4,682)=307.27, \mathrm{p}<0.001$.

As shown in Table 3, the final model included all pharmacy and home context variables, the two-way interaction term and three covariates significantly associated with nonadherence likelihood. In the pharmacy context, picking up fewer prescriptions from the pharmacy, taking fewer trips to the pharmacy and never, rarely or sometimes using mail order compared with always using mail order pharmacy services were significantly associated with nonadherence likelihood. In the home context, reporting not being satisfied with the medication organization method used was associated with increased nonadherence likelihood, compared with those who reported satisfaction. The odds ratios for pillbox use and pill pouches indicate these methods are associated with decreased nonadherence likelihood, compared with using the original packaging. However, the interaction between being bothered with managing medications and the method used to organize medications remained significant in the multivariable model and this interaction was observed among the group using pill pouches and reporting being bothered by managing medications. Using pill 
Table I Respondent Demographic and Medication-Taking Characteristics

\begin{tabular}{|c|c|c|c|c|}
\hline & Total Sample, N=4682 & Nonadherent, $n=\mid 209$ & Adherent, $n=3473$ & p-value \\
\hline \multicolumn{5}{|l|}{ Demographics } \\
\hline Age, mean (SD) & $52.73(16.43)$ & $50.18(16.46)$ & $53.62(16.33)$ & $<0.00 I^{*}$ \\
\hline $\begin{array}{l}\text { Sex, n (\%) } \\
\text { Male } \\
\text { Female }\end{array}$ & $\begin{array}{l}1890(40.4) \\
2792(59.6)\end{array}$ & $\begin{array}{l}432(35.7) \\
777(64.3)\end{array}$ & $\begin{array}{l}1458(42.0) \\
20 I 5(58.0)\end{array}$ & $<0.001 *$ \\
\hline $\begin{array}{l}\text { Educational level, n (\%) } \\
\text { Less than High School } \\
\text { High School } \\
\text { Some College } \\
\text { Bachelors or higher }\end{array}$ & $\begin{array}{l}249(5.3) \\
1303(27.8) \\
1719(36.7) \\
1411(30.1)\end{array}$ & $\begin{array}{l}65(5.4) \\
303(25.1) \\
481(39.8) \\
360(29.8)\end{array}$ & $\begin{array}{l}184(5.3) \\
1000(28.8) \\
1238(35.6) \\
1051(30.3)\end{array}$ & $0.033^{*}$ \\
\hline $\begin{array}{l}\text { Education as dichotomous, } n(\%) \\
\text { High School or less } \\
\text { More than High School }\end{array}$ & $\begin{array}{l}1552(33.1) \\
3130(66.9)\end{array}$ & $\begin{array}{l}368(30.4) \\
84 I(69.6)\end{array}$ & $\begin{array}{l}\text { II } 84(34.1) \\
2289(65.9)\end{array}$ & $0.020^{*}$ \\
\hline $\begin{array}{l}\text { Race, } \mathrm{n}(\%) \\
\text { White } \\
\text { Black or African American } \\
\text { American Indian/Alaska Native } \\
\text { Asian } \\
\text { Native Hawaiian or other Pacific Islander } \\
\text { Other race }\end{array}$ & $\begin{array}{l}1917(40.9) \\
334(7.1) \\
61(1.3) \\
72(1.5) \\
5(0.1) \\
72(1.5)\end{array}$ & $\begin{array}{l}472(39.0) \\
88(7.3) \\
18(1.5) \\
21(1.7) \\
2(0.2) \\
20(1.7)\end{array}$ & $\begin{array}{l}1445(41.6) \\
246(7.1) \\
43(1.2) \\
51(1.5) \\
3(0.1) \\
52(1.5)\end{array}$ & $\begin{array}{l}0.282 \\
0.466 \\
0.396 \\
0.395 \\
0.406 \\
0.473\end{array}$ \\
\hline $\begin{array}{l}\text { Ethnicity, } \mathrm{n}(\%) \\
\text { Hispanic or Latin } \\
\text { Not Hispanic or Latin }\end{array}$ & $\begin{array}{l}213(4.5) \\
2167(46.3)\end{array}$ & $\begin{array}{l}5 \mathrm{I}(4.2) \\
547(45.2)\end{array}$ & $\begin{array}{l}162(4.7) \\
1620(46.6)\end{array}$ & 0.498 \\
\hline $\begin{array}{l}\text { Income, } n(\%) \\
\$ 19,999 \text { or less } \\
\$ 20,000 \text { to } \$ 39,999 \\
\$ 40,000 \text { to } \$ 59,999 \\
\$ 60,000 \text { to } \$ 99,999 \\
\$ 100,000 \text { or greater }\end{array}$ & $\begin{array}{l}795(17.0) \\
1083(23.1) \\
830(17.7) \\
1046(22.3) \\
928(19.8)\end{array}$ & $\begin{array}{l}203(16.8) \\
258(21.3) \\
234(19.4) \\
288(23.8) \\
226(18.7)\end{array}$ & $\begin{array}{l}592(17.0) \\
825(23.8) \\
596(17.2) \\
758(21.8) \\
702(20.2)\end{array}$ & $0.117^{*}$ \\
\hline $\begin{array}{l}\text { Insurance Coverage for Medications, } n(\%) \\
\text { Yes } \\
\text { No }\end{array}$ & $\begin{array}{l}4444(94.9) \\
238(5.1)\end{array}$ & $\begin{array}{l}1147(94.9) \\
62(5.1)\end{array}$ & $\begin{array}{l}3297(94.9) \\
176(5.1 \%)\end{array}$ & 0.934 \\
\hline $\begin{array}{l}\text { Type(s) of Insurance, n(\%) } \\
\text { Work insurance } \\
\text { Individual health plan } \\
\text { Medicare } \\
\text { Medicaid } \\
\text { Veteran Affairs } \\
\text { Healthcare exchange } \\
\text { Other insurance coverage } \\
\text { No insurance }\end{array}$ & $\begin{array}{l}1867(40.0) \\
5014(10.8) \\
1409(30.1) \\
846(18.1) \\
182(3.9) \\
220(4.7) \\
108(2.3) \\
238(5.1)\end{array}$ & $\begin{array}{l}516(42.1) \\
113(9.2) \\
342(27.9) \\
223(18.2) \\
50(4.1) \\
63(5.1) \\
27(2.2) \\
62(5.1)\end{array}$ & $\begin{array}{l}1375(39.0) \\
401(11.4) \\
1093(31.0) \\
631(17.9) \\
136(3.9) \\
158(4.5) \\
81(2.3) \\
179(5.1)\end{array}$ & \\
\hline \multicolumn{5}{|l|}{ Medication characteristics } \\
\hline $\begin{array}{l}\text { Total Number of Prescribed Oral Medications Taken Daily } \\
\text { One }\end{array}$ & 1038 (22.2) & 27I (22.4) & 767 (22.1) & $0.08^{*}$ \\
\hline
\end{tabular}

(Continued) 
Table I (Continued).

\begin{tabular}{|c|c|c|c|c|}
\hline & Total Sample, $N=4682$ & Nonadherent, $n=\mid 209$ & Adherent, $n=3473$ & p-value \\
\hline Two & $952(20.3)$ & $27 \mid(22.4)$ & $681(19.6)$ & \\
\hline Three or more & $2692(57.5)$ & $667(55.2)$ & $2025(58.3)$ & \\
\hline Total oral prescriptions per day, mean (SD) & $3.9(3.7)$ & $3.77(3.4)$ & $4.0(3.8)$ & \\
\hline Total non-oral prescriptions per day, mean (SD) & $0.67(2.5)$ & $0.64(2.0)$ & $0.68(2.6)$ & 0.648 \\
\hline Frequency of oral prescription, $n(\%)$ & & & & $0.046 *$ \\
\hline Once a day & $2221(47.4)$ & $555(45.9)$ & $1666(48.01)$ & \\
\hline 2 times a day & $1806(38.6)$ & $496(4 I .0)$ & $1310(37.7)$ & \\
\hline 3 or more times a day & $655(14.0)$ & $158(13.1)$ & $497(14.3)$ & \\
\hline Changes in prescription in the past year, $n(\%)$ & & & & $<0.00 I^{*}$ \\
\hline No Changes & $1926(41.1)$ & $418(34.6)$ & $1508(43.5)$ & \\
\hline Changes occurred & $2756(58.9)$ & $791(65.4)$ & $1965(56.6)$ & \\
\hline
\end{tabular}

Notes: *Selection criteria $\mathrm{p}<0.25,{ }^{\dagger}$ Respondents could have selected more than one option.

Table 2 Comparisons of Pharmacy and Home Context Variables Between Medication Adherence Groups

\begin{tabular}{|c|c|c|c|c|}
\hline Variables & $\begin{array}{l}\text { Total } \\
\text { Sample, } \\
\text { N=4682 }\end{array}$ & $\begin{array}{l}\text { Nonadherent, } \\
n=1209\end{array}$ & $\begin{array}{l}\text { Adherent, } \\
\mathrm{n}=3473\end{array}$ & p-value \\
\hline \multicolumn{5}{|l|}{ Pharmacy Context } \\
\hline Total number of prescriptions picked up per pharmacy visit, mean (SD) & $2.6(2.4)$ & $2.4(1.9)$ & $2.8(2.5)$ & $0.001 *$ \\
\hline $\begin{array}{l}\text { Total number of trips to the pharmacy taken in the past } 6 \text { months to pick up } \\
\text { prescriptions? }\end{array}$ & $9.1(9.41)$ & $8.4(7.2)$ & $9.4(10.1)$ & $<0.001 *$ \\
\hline $\begin{array}{l}\text { How often do you use mail order/home delivery pharmacy? } \\
\text { Always } \\
\text { Some of the time } \\
\text { Rarely } \\
\text { Never }\end{array}$ & $\begin{array}{l}392(8.4) \\
808(17.3) \\
553(11.8) \\
2929(62.6)\end{array}$ & $\begin{array}{l}72(6.0) \\
238(19.7) \\
192(15.9) \\
707(58.5)\end{array}$ & $\begin{array}{l}320(9.2) \\
570(16.4) \\
361(10.4) \\
2222(64.0)\end{array}$ & $<0.001 *$ \\
\hline \multicolumn{5}{|l|}{ Home Context } \\
\hline $\begin{array}{l}\text { Organization method } \\
\text { Original packaging } \\
\text { Pillboxes } \\
\text { Pill pouches } \\
\text { Other }\end{array}$ & $\begin{array}{l}2367(50.6) \\
2039(43.5) \\
126(2.7) \\
150(3.2)\end{array}$ & $\begin{array}{l}664(54.9) \\
469(38.8) \\
32(2.6) \\
44(3.6)\end{array}$ & $\begin{array}{l}1703(49.0) \\
1570(45.2) \\
94(2.7) \\
106(3.1)\end{array}$ & $0.001 *$ \\
\hline $\begin{array}{l}\text { Bothered by Managing Medications } \\
\text { Not bothered } \\
\text { Bothered }\end{array}$ & $\begin{array}{l}2218(47.4) \\
2464(52.6)\end{array}$ & $\begin{array}{l}381(31.5) \\
828(68.5)\end{array}$ & $\begin{array}{l}1837(52.9) \\
1636(47.1)\end{array}$ & $<0.00 I^{*}$ \\
\hline $\begin{array}{l}\text { Satisfied with Organization } \\
\text { Satisfied } \\
\text { Not satisfied }\end{array}$ & $\begin{array}{l}4579(97.8) \\
103(2.2)\end{array}$ & $\begin{array}{l}1158(95.8) \\
5 I(4.2)\end{array}$ & $\begin{array}{l}3421(98.5) \\
52(1.5)\end{array}$ & $<0.00 I^{*}$ \\
\hline
\end{tabular}

Note: *Selection criteria $\mathrm{p}<0.25$.

pouches and reporting being bothered by organizing medications was associated with an increased nonadherence likelihood.
Younger age was significantly associated with nonadherence likelihood, in which each one-year reduction in age increased the odds of nonadherence by a factor of 1.01 
Table 3 Final Logistic Regression Model of Variables Associated with Nonadherence Likelihood

\begin{tabular}{|c|c|c|}
\hline & OR $[95 \% \mathrm{Cl}]$ & $P$ value \\
\hline \multicolumn{3}{|l|}{ Demographic Characteristics } \\
\hline Age & $0.993[0.988,0.997]$ & $<0.001$ \\
\hline Sex & & \\
\hline Female compared to ${ }^{\wedge}$ male & $1.237[1.075,1.425]$ & $<0.001$ \\
\hline $\begin{array}{l}\text { Medication Characteristics } \\
\text { Changes in prescription in the past } \\
\text { Yes compared with ^no changes }\end{array}$ & $1.415[1.224,1.635]$ & $<0.001$ \\
\hline $\begin{array}{l}\text { Pharmacy Context } \\
\text { Number of prescriptions picked up from pharmacy } \\
\text { Separate trips to pharmacy } \\
\text { Mail order ^Always compared to some of the time, rarely or never }\end{array}$ & $\begin{array}{l}0.957[0.925,0.990] \\
0.982[0.973,0.991] \\
1.712[1.299,2.257]\end{array}$ & $\begin{array}{l}0.010 \\
<0.001 \\
<0.001\end{array}$ \\
\hline Home Context & & \\
\hline $\begin{array}{l}\text { Organization Method ^ Original packaging } \\
\text { Pillbox } \\
\text { Pill pouch } \\
\text { Other method/device }\end{array}$ & $\begin{array}{l}- \\
0.723[0.569,0.919] \\
0.150[0.036,0.624] \\
0.732[0.378,1.416]\end{array}$ & $\begin{array}{l}0.004 \\
0.008 \\
0.009 \\
0.354\end{array}$ \\
\hline $\begin{array}{l}\text { Bothered by Managing Medications } \\
\text { Bothered compared with ^^not bothered }\end{array}$ & $2.132[1.766,2.575]$ & $<0.001$ \\
\hline $\begin{array}{l}\text { Satisfaction with organization } \\
\text { Not satisfied compared with ^satisfied }\end{array}$ & $2.126[1.417,3.189]$ & $<0.001$ \\
\hline $\begin{array}{l}\text { Organization method by bothered managing medications } \\
\text { Pillbox by bothered } \\
\text { Pill pouch by bothered } \\
\text { Other by bothered }\end{array}$ & $\begin{array}{l}- \\
1.113[0.828,1.496] \\
8.280[1.837,37.314] \\
2.207[0.976,4.992]\end{array}$ & $\begin{array}{l}0.012 \\
0.486 \\
0.006 \\
0.057\end{array}$ \\
\hline
\end{tabular}

Note: ^Reference category.

(95\% CI: $1.00-1.01)$. Females had 1.237 times [95\% CI: 1.075-1.425] higher odds for reporting nonadherence likelihood than males and changes in medication had a 1.415 times [95\% CI:1.224-1.635] higher odds for nonadherence compared with those reporting no changes. The covariates of education level, income and total number of oral medications taken daily did not significantly contribute to nonadherence likelihood and were not included in the final model.

\section{Discussion}

Findings from this secondary analysis of a large data set demonstrate that aspects of how adults manage and organize medications in pharmacy and home contexts are associated with their likelihood of being nonadherent, while controlling for age, sex, and changes to medications. Our findings add to the body of literature that has identified a substantial number of factors associated with nonadherence, ${ }^{2,23}$ while uniquely contributing understanding of inconveniences (or conveniences) in the management of medications in pharmacy and home contexts. Specifically, our findings indicate that the way that patients obtain their medications from a pharmacy, how they manage and organize their medications at home, including whether they are not satisfied with and bothered by medication management, are aspects that can affect the likelihood of adults taking medications as prescribed.

While our main finding is consistent with the variables that we hypothesized to be associated with nonadherence in our conceptual model and guided by the MACO framework, ${ }^{10,18}$ the directionality of some of the associations with nonadherence was surprising. In particular, fewer separate trips made to the pharmacy and fewer numbers of prescriptions picked up at each visit were related to nonadherence. While this finding was surprising, similar findings have been reported elsewhere. ${ }^{24-26}$ One plausible explanation for fewer trips and 
prescriptions picked up from the pharmacy is that people may be obtaining some medications from mail order and also from a retail brick and mortar pharmacy which may negate the convenience aspects that mail order affords and subsequently lead to nonadherence. For example, Choudry and colleagues ${ }^{25}$ observed that filling fewer medications per pharmacy visit was associated with less adherence, a finding that was particularly apparent among those using both retail and mail order services. Similarly, we found that nearly $20 \%$ of those that reported nonadherence sometimes used mail order, signaling that perhaps they were obtaining medications using both mail order and picking up prescriptions from a pharmacy. It stands to reason that getting medications from multiple sources and methods may increase management complexity. To date, emphasis has been placed on picking up prescriptions from multiple different pharmacies, ${ }^{27,28}$ and not necessarily on different modes. Our findings and the existing literature reflect the importance of fully understanding individuals' experiences in the pharmacy context and simplifying their medication management to make it more convenient. Opportunities like medication synchronization, ${ }^{29,30}$ having a home pharmacy, ${ }^{31}$ and even a single mode for obtaining medications (only retail or only mail) might be important strategies to improve adherence.

The relationship between the type of organization method and nonadherence is particularly meaningful for intervention design. In the home context, with the exception of one subgroup, we found that pill boxes and pill pouches significantly reduced the likelihood of nonadherence compared with those who reported keeping their medications in the original packaging (ie, bottles). This finding is consistent with findings from a systematic review of 30 studies $^{32}$ and a meta-analysis of 52 studies $^{33}$ that both provide evidence for the effectiveness of packaging interventions (like pillboxes and pill pouches) to improve adherence. However, in the present study, we found that a small group of individuals using pill pouches reported they were bothered by managing and organizing medications which significantly increased their likelihood of being nonadherent. This finding suggests that other factors may mediate or moderate the effects of organization devices. Additionally, pill pouches can be purchased and filled at home, similar to pillboxes or they can come pre-packaged from a pharmacy and be delivered to home. In the present study, we are unable to determine if individuals using pill pouches were receiving them by mail or packaging them themselves. Pill pouches that come pre-filled and delivered directly to the home may be an approach to reduce perceived bother from medication management and organization. This builds on our findings related to the pharmacy context previously described yet requires further study and consideration for improving individuals' satisfaction with selected methods.

While medication delivery to the home offers convenience, it does not resolve all of the complexities and other inconveniences involved with medication management. Satisfaction, or rather not being satisfied with one's method of managing and organizing medications, increased the odds of nonadherence likelihood by two-fold in our study. Similar findings have linked satisfaction with nonadherence; ${ }^{34-38}$ however, these other studies focused on different aspects of satisfaction like provider communication ${ }^{34-36}$ and satisfaction with medications ${ }^{35,37}$ rather than satisfaction with the medication management and organization aspects, as in our study. Recent evidence suggests that packaging can improve adherence, but the maximal impact on adherence and clinical outcomes stems from the combination of the packaging with medication therapy management services. ${ }^{39}$ This finding, combined with understanding of the inconvenience factors identified in the present study, underscores the importance of delivering interventions that make medication management more convenient as individuals manage medication aspects across both the pharmacy and home contexts.

Given the findings in the current study, future intervention research should focus on supporting individuals to optimize the benefits that these different types of organization methods have to offer combined with the important aspects of the pharmacy context. Individualized interventions are needed in order to optimize the effects of medication management and organization factors to ultimately improve adherence.

\section{Limitations}

There are several aspects of our study which may limit the strength of the interpretations. First, this is a secondary analysis of survey data. The survey was designed to understand individuals' experiences managing medications and was not specifically designed to measure all the potential factors influencing nonadherence. Second, because responses were self-reported, we had no means of confirming actual nonadherence. Third, our single question used as a measure of nonadherence did not specify a time-frame/recall period, which has been shown to improve the accuracy of selfreported data. ${ }^{40}$ Instead, the survey item asked about nonadherence likelihood, which reflects intention towards future behavior, rather than representing past behavior. Although the selected self-report measure of nonadherence did not 
meet these requirements, the percentage of individuals selfreporting nonadherence in our study is consistent with other reports of nonadherence $\mathrm{e}^{2,38}$ and consistent with reports that have used measures of nonadherence with established evidence of reliability and validity. ${ }^{38}$ Fourth, this is a crosssectional study design and our measure of nonadherence did not distinguish adherence by initiation, implementation and discontinuation of the treatment regimen, which are different processes of adherence that occur over time. ${ }^{3}$

Notwithstanding these limitations, the findings can be readily used to develop individual-level interventions. A key strength in our study is that our multivariable model reflects person-centric convenience factors that are largely modifiable. Our analysis suggests that always using home delivery of medications and supporting individuals to manage and organize medications, using strategies that do not bother them and that they are satisfied with, may reduce nonadherence.

\section{Conclusion}

The present study suggests that interventions that improve convenience may address an unmet need for patients and have a positive impact on adherence. Though reasons for non adherence are multi-factorial, this study suggests that convenience factors are important - both pharmacy convenience (number of prescriptions picked up per trip and number of trips to the pharmacy and use of home-delivery) and home management convenience (type of, satisfaction with, and burden of organizational methods). Improving nonadherence should focus on these largely modifiable convenience factors. Behavioral economics' "Nudge Theory" emphasizes the importance of increasing ease and convenience to steer people's behavior in a predictable way. Based on this theory, adherence should improve by making it convenient for patients to initiate and manage their medication. Emerging solutions that reduce time and burden associated with organizing and managing medications, such as pouch packing solutions combined with other interventions, that make organizing and obtaining prescriptions refills convenient, likely have the potential to improve nonadherence. Furthermore, optimizing existing organizational methods and streamlining interactions with pharmacies, be it with brick and mortar or online pharmacy services may make medication management aspects more satisfying and further improve adherence.

\section{Acknowledgments}

The authors thank the Becton, Dickinson and Company and Ipsos teams for their assistance in developing the larger study in which the data reported here was collected.
In addition, we express appreciation to Kari Meyers, Yan Xiong, and Sneh Ringwala (Becton, Dickinson and Company) for their critical reading of and helpful commentary on earlier drafts of this paper. Becton, Dickinson and Company funded this research.

\section{Disclosure}

Rebecca J Bartlett Ellis and Todd Ruppar received consulting fees from Becton, Dickinson and Company for this research. Ellis has a patent method and system for autonomously measuring, recording, and reporting changes in the interior content of containers (AKA "Smart Pillbox") pending. Deanna Hertz is an employee of Ipsos, the consultancy that received a fee from Becton Dickinson for this research. Patrick Callahan was an employee of Becton, Dickinson and Company at the time the manuscript was prepared. The authors report no other conflicts of interest in this work.

\section{References}

1. Centers for Disease Control and Prevention's (CDC) National Center for Health Statistics (NCHS). FastStats. Table 79. Prescription drug use in the past 30 days, by sex, race and Hispanic origin, and age: United States, through 2011-2014. February 26, 2019. Available from: https://www.cdc. gov/nchs/fastats/drug-use-therapeutic.htm. Accessed April 15, 2019.

2. Sabaté E, eds; World Health Organization. Adherence to Long-Term Therapies: Evidence for Action. Geneva: World Health Organization; 2003.

3. Vrijens B, De Geest S, Hughes DA, et al. A new taxonomy for describing and defining adherence to medications. Br J Clin Pharmacol. 2012;73 (5):691-705. doi:10.1111/j.1365-2125.2012.04167.x

4. McDermott MM, Schmitt B, Wallner E. Impact of medication nonadherence on coronary heart disease outcomes: a critical review. Arch Intern Med. 1997;157(17):1921-1929. doi:10.1001/archinte.1997.00440380023002

5. New England Healthcare Institute. Thinking outside the pillbox: a system-wide approach to improving patient medication adherence for chronic disease; NEHI. Available from: https://www.nehi.net/writable/ publication_files/file/pa_issue_brief_final.pdf. Accessed April 10, 2019.

6. Mann DM, Woodward M, Muntner P, Falzon L, Kronish I. Predictors of nonadherence to statins: a systematic review and meta-analysis. Ann Pharmacother. 2010;44(9):1410-1421. doi:10.1345/aph.1P150

7. Karamanidou C, Clatworthy J, Weinman J, Horne R. A systematic review of the prevalence and determinants of nonadherence to phosphate binding medication in patients with end-stage renal disease. BMC Nephrol. 2008;9(1):2. doi:10.1186/1471-2369-9-2

8. Davies MJ, Gagliardino JJ, Gray LJ, Khunti K, Mohan V, Hughes R. Real-world factors affecting adherence to insulin therapy in patients with Type 1 or Type 2 diabetes mellitus: a systematic review. Diabet Med J Br Diabet Assoc. 2013;30(5):512-524. doi:10.1111/dme.12128

9. Kardas P, Lewek P, Matyjaszczyk M. Determinants of patient adherence: a review of systematic reviews. Front Pharmacol. 2013;4:91. doi:10.3389/fphar.2013.00091

10. Bartlett Ellis RJ, Welch JL. Medication-taking behaviours in chronic kidney disease with multiple chronic conditions: a meta-ethnographic synthesis of qualitative studies. J Clin Nurs. 2017;26(5-6):586-598. doi:10.1111/jocn. 13588

11. Kripalani S, Henderson LE, Jacobson TA, Vaccarino V. Medication use among inner-city patients after hospital discharge: patient-reported barriers and solutions. Mayo Clin Proc. 2008;83(5):529-535. doi:10.4065/ 83.5.529 
12. Bartlett Ellis RJ, Ganci A, Head KJ, Ofner S. Characteristics of adults managing vitamins/supplements and prescribed medications - who is using, not using, and abandoning use of pillboxes? A descriptive study. Clin Nurse Spec. 2018;32(5):231-239. doi:10.1097/NUR.0000000000000395

13. Conn VS, Ruppar TM. Medication adherence outcomes of 771 intervention trials: systematic review and meta-analysis. Prev Med. 2017;99:269-276. doi:10.1016/j.ypmed.2017.03.008

14. hhs.gov. Human subject regulations decision charts. HHS.gov. February 25, 2016. Available from: https://www.hhs.gov/ohrp/regulations-andpolicy/decision-charts/index.html. Accessed January 14, 2020.

15. KnowledgePanel ${ }^{\circledR}$. Available from: https://join.knpanel.com/about. html. Accessed July 11, 2019.

16. Naguib A, Ringwala S, Callahan P, Swenson D, Hale B Burden of medication nonadherence associated with convenience when acquiring and organizing medications in the U.S. adult population. In: ASHP Midyear Clinical Meeting \& Exhibition. Anaheim, CA; 2018.

17. Naguib A, Ringwala S, Callahan P, Swenson D, Hale B Medication errors and adverse drug events associated with complexities organizing and administering medications in a U.S. adult population. In: ASHP Summery Meeting and Exhibition 2018. Denver, CO; 2018.

18. Bartlett Ellis RJ Medication-taking across the care continuum and adherence-related outcomes (MACO) framework; 2015. Available from:http://hdl.handle.net/1805/9015. Accessed January 24, 2020.

19. Feldman B, Fredericksen R, Crane P, et al. Evaluation of the single-item self-rating adherence scale for use in routine clinical care of people living with HIV. AIDS Behav. 2013;17(1):307-318. doi:10.1007/s10461-012-0326-7

20. Gonzalez JS, Schneider HE, Wexler DJ, et al. Validity of medication adherence self-reports in adults with Type 2 diabetes. Diabetes Care. 2013;36(4):831-837. doi:10.2337/dc12-0410

21. Wu J-R, DeWalt DA, Baker DW, et al. A single-item self-report medication adherence question predicts hospitalization and death in patients with heart failure. J Clin Nurs. 2014;23:2554-2564. doi:10.1111/jocn.12471

22. Hosmer DW Jr, Lemeshow S, Rodney X. Sturdivant. In: Applied Logistic Regression. 3rd ed. (C) John Wiley \& Sons, Inc; 2013:91.

23. Feehan M, Morrison MA, Tak C, Morisky DE, DeAngelis MM, Munger MA. Factors predicting self-reported medication low adherence in a large sample of adults in the US general population: a cross-sectional study. BMJ Open. 2017;7(6):e014435. doi:10.1136/ bmjopen-2016-014435

24. Barnes B, Hincapie AL, Luder H, Kirby J, Frede S, Heaton PC. Appointment-based models: a comparison of three model designs in a large chain community pharmacy setting. $J$ Am Pharm Assoc. 2018;58(2):156-162.e1. doi:10.1016/j.japh.2018.01.005

25. Choudhry NK, Fischer MA, Avorn J, et al. The implications of therapeutic complexity on adherence to cardiovascular medications | cardiology | JAMA internal medicine | JAMA Network. Arch Intern Med. 2011;171(9):814.822. doi:10.1001/archinternmed.2010.495

26. Ross A, Jami H, Young HA, Sync KR. Swim: the impact of medication consolidation on adherence in medicaid patients. J Prim Care Community Health. 2013;4(4):240-244. doi:10.1177/2150131913486481
27. Marcum ZA, Driessen J, Thorpe CT, Gellad WF, Donohue JM. Effect of multiple pharmacy use on medication adherence and drug-drug interactions in older adults with medicare part D. J Am Geriatr Soc. 2014;62(2):244-252. doi:10.1111/jgs.12645

28. Bazargan M, Smith J, Movassaghi M, et al. Polypharmacy among underserved older African American adults. $J$ Aging Res. 2017;2017:6026358. doi:10.1155/2017/6026358

29. Krumme AA, Isaman DL, Stolpe SF, Dougherty S, Choudhry NK. Prevalence, effectiveness, and characteristics of pharmacy-based medication synchronization programs. Am J Manag Care. 2016;22 (3):179-186.

30. Doshi JA, Lim R, Li P, et al. A synchronized prescription refill program improved medication adherence. Health Aff Proj Hope. 2016;35(8):1504-1512. doi:10.1377/hlthaff.2015.1456

31. Stafford RA, Garrett LN, Bates KA, et al. Development and implementation of a collaboration between a patient-centered medical home and community pharmacy. J Am Pharm Assoc. 2019. doi:10.1016/j.japh.2019.09.022

32. Boeni F, Spinatsch E, Suter K, Hersberger KE, Arnet I. Effect of drug reminder packaging on medication adherence: a systematic review revealing research gaps. Syst Rev. 2014;3:29. doi:10.1186/2046-40533-29

33. Conn VS, Ruppar TM, Chan KC, Dunbar-Jacob J, Pepper GA, De Geest S. Packaging interventions to increase medication adherence: systematic review and meta-analysis. Curr Med Res Opin. 2015;31 (1):145-160. doi:10.1185/03007995.2014.978939

34. Jin H, Kim Y, Rhie SJ. Factors affecting medication adherence in elderly people. Patient Prefer Adherence. 2016;10:2117-2125. doi:10.2147/PPA.S118121

35. Park HY, Seo SA, Yoo H, Lee K. Medication adherence and beliefs about medication in elderly patients living alone with chronic diseases. Patient Prefer Adherence. 2018;12:175-181. doi:10.2147/ PPA.S151263

36. Linn AJ, van Weert JCM, van Dijk L, Horne R, Smit EG. The value of nurses' tailored communication when discussing medicines: exploring the relationship between satisfaction, beliefs and adherence. $J$ Health Psychol. 2016;21(5):798-807. doi:10.1177/1359105314539529

37. Alam MM, Sikdar P, Kumar A, Mittal A. Assessing adherence and patient satisfaction with medication: validation of TSQM in emerging markets. Int J Pharm Healthc Mark. 2018;12(4):409-432. doi:10.1108/IJPHM-102016-0053

38. Belaiche S, Décaudin B, Dharancy S, Noel C, Odou P, Hazzan M. Factors relevant to medication non-adherence in kidney transplant: a systematic review. Int J Clin Pharm. 2017;39(3):582-593. doi:10.1007/s11096-0170436-4

39. Pinto S, Simon A, Osundina F, Jordan M, Ching D. Study to measure the impact of pharmacists and pharmacy services (STOMPP) on medication non-adherence: medication adherence and clinical outcomes. Innov Pharm. 2018;9(1):11. doi:10.24926/iip.v9i1.1104

40. Stirratt MJ, Dunbar-Jacob J, Crane HM, et al. Self-report measures of medication adherence behavior: recommendations on optimal use. Transl Behav Med. 2015;5(4):470-482. doi:10.1007/s13142-0150315-2
Patient Preference and Adherence

\section{Publish your work in this journal}

Patient Preference and Adherence is an international, peer-reviewed, open access journal that focuses on the growing importance of patient preference and adherence throughout the therapeutic continuum. Patient satisfaction, acceptability, quality of life, compliance, persistence and their role in developing new therapeutic modalities and compounds to optimize clinical outcomes for existing disease states are major areas of interest for the journal. This journal has been accepted for indexing on PubMed Central. The manuscript management system is completely online and includes a very quick and fair peer-review system, which is all easy to use. Visit http:// www.dovepress.com/testimonials.php to read real quotes from published authors. 